\title{
High-definition optical coherence tomography intrinsic skin ageing assessment in women: a pilot study
}

\author{
M. A. L. M. Boone ${ }^{1}$ M. Suppa ${ }^{1}$ A. Marneffe ${ }^{1}$ - M. Miyamoto ${ }^{1}$ G. B. E. Jemec ${ }^{2}$. \\ V. Del Marmol ${ }^{1}$
}

Received: 22 January 2015/Revised: 19 April 2015/ Accepted: 14 May 2015/Published online: 12 June 2015

(C) The Author(s) 2015. This article is published with open access at Springerlink.com

\begin{abstract}
Several non-invasive two-dimensional techniques with different lateral resolution and measurable depth range have proved to be useful in assessing and quantifying morphological changes in skin ageing. Among these, only in vivo microscopy techniques permit histometric measurements in vivo. Qualitative and quantitative assessment of chronological (intrinsic) age-related (IAR) morphological changes of epidermis, dermo-epidermal junction (DEJ), papillary dermis (PD), papillary-reticular dermis junction and reticulardermis (RD) have been performed by high-definition optical coherence tomography in real time 3-D. HD-OCT images were taken at the internal site of the right upper arm. Qualitative HD-OCT IAR descriptors were reported at skin surface, at epidermal layer, DEJ, PD and upper RD. Quantitative evaluation of age-related compaction and backscattered intensity or brightness of different skin layers was performed by using the plugin plot $z$-axis profile of Image ${ }^{\circledR}$ software permitting intensity assessment of HD-OCT (DICOM) images (3$\mathrm{D}$ images). Analysis was in blind from all clinical information. Sixty, fair-skinned (Fitzpatrick types I-III) healthy females were analysed retrospectively in this study. The subjects belonged to three age groups: twenty in group I aged 20-39, twenty in group II aged 40-59 and twenty in group III aged 60-79. Only intrinsic ageing in women has
\end{abstract}

M. A. L. M. Boone

dr.boone@scarlet.be

1 Department of Dermatology, Université Libre de Bruxelles, Hôpital Erasme, Meise, Belgium

2 Health Sciences Faculty, Department of Dermatology, Roskilde Hospital, University of Copenhagen, Roskilde, Denmark been studied. Significant age-related qualitative and quantitative differences could be noticed. IAR changes in dermal matrix fibers morphology/organisation and in microvasculature were observed. The brightness and compaction of the different skin layers increased significantly with intrinsic skin ageing. The depth of visibility of fibers in RD increased significantly in the older age group. In conclusion, HD-OCT allows 3-D in vivo and real time qualitative and quantitative assessment of chronological (intrinsic) age-related morphological skin changes at high resolution from skin surface to a depth of the superficial reticular dermis.

Keywords High-definition optical coherence tomography · Intrinsic skin ageing - Qualitative and quantitative assessment

\section{Introduction}

Skin ageing has become an important health market [34]. Many of the treatments offered claim to modulate processes involved in skin ageing. Testing the efficacy of these therapies is important for consumers, dermatologists, cosmetic industry and regulatory authorities [36, 44].

For the assessment of molecular mechanisms involved in intrinsic skin ageing, invasive tests are clearly the gold standard $[2,32,50]$. However, the invasive nature of skin biopsy is not the most suitable method to investigate skin ageing in the general population. Skin ageing is a physiological process and, for obvious ethical reasons, efficacy testing of anti-ageing treatments should therefore be based on non-invasive methods [11].

Several non-invasive two-dimensional imaging techniques with different lateral resolution and measurable 
Table 1 Absolute and relative frequencies of intrinsic skin ageing related morphologic parameters imaged by 3-D HD-OCT in standard colour setting

\begin{tabular}{llll}
\hline & Young-aged group $(N=20)$ & Middle-aged group $(N=20)$ & Old-aged group $(N=20)$ \\
\hline Furrow pattern & & & $0(0.0 \%)$ \\
Small rhomboidal & $19(95.0 \%)(p<0.001) *$ & $1(5.0 \%)$ & $1(5.0 \%)$ \\
Large rhomboidal & $1(5.0 \%)$ & $11(55.0 \%)(p<0.001)$ & $5(25.0 \%)$ \\
Linear & $0(0.0 \%)$ & $7(35.0 \%)($ Not significant $)$ & $14(70.0 \%)(p<0.001)$ \\
Disarranged & $0(0.0 \%)$ & $1(5.0 \%)$ & $0(0.0 \%)$ \\
Flattening & & & $20(100.0 \%)(p<0.001)$ \\
Cross-sectional & $20(100.0 \%)(p<0.01)$ & $15(75.0 \%)$ & $0(0.0 \%)$ \\
$\quad$ Jagged & $0(0.0 \%)$ & $5(25.0 \%)$ & $0(0.00 \%)$ \\
$\quad$ Flat & & $15(75.0 \%)$ & $20(100.0 \%)(p<0.001)$ \\
En face & $20(100.0 \%)(p<0.01)$ & $10(50.0 \%)(p<0.01)$ & $5(25.0 \%)$ \\
$\quad$ Papillary rings present & $1(5.0 \%)$ & & \\
Irregular rings & $0(0.0 \%)$ & & \\
$\quad$ Papillary rings absent & & & \\
\hline
\end{tabular}

* $p$ values have been mentioned whenever appropriate; for details see "Results"

depth range have proved to be useful in assessing and quantifying morphological changes in skin ageing $[1,10]$. Among these, only in vivo microscopy techniques such as reflectance confocal microscopy (RCM) [30, 40, 42, 51] and multiphoton laser scanning tomography (MPT) $[21,23$, $24,38]$ permit cellular resolution in vivo. In vivo techniques without cellular resolution dealing with skin ageing are high-frequency ultrasound (HF-US) [16-19, 41, 43, 49] and conventional optical coherence tomography (OCT) $[13,25,31,33,35]$.

High-definition OCT (HD-OCT) is a recently introduced non-invasive technology based on the principle of low coherence interferometry [4-9, 15]. This method permits real time three-dimensional (3-D) imaging with cellular resolution up to $570 \mu \mathrm{m}$ depth. This enables visualization of cells in their micro-architectural environment at up to the superficial reticular dermis. It was recently demonstrated that real time 3-D imaging provides accurate information on dermal matrix fibre organisation and microvasculature volume [9].

The aim of this study is the qualitative and quantitative 3-D HD-OCT assessment of intrinsic age-related (IAR) morphological skin changes [46] from skin surface up to the superficial reticular dermis.

\section{Methods}

\section{Study sample}

HD-OCT images of 60, fair-skinned, healthy females (skin types I-III) were retrieved from first author's private practice for inclusion in this retrospective study. Inclusion criteria were (1) availability of good quality HD-OCT images of normal skin at inner site of upper arm and (2) absence of signs of actinic damage in this anatomic region. These images were taken during daily practice as control/ reference HD-OCT images in comparison with HD-OCT images of affected skin. We conformed to the Helsinki Declaration with respect to human subjects in biomedical research. All international rules governing clinical investigation of human subjects were strictly followed. Approval from local ethical committee and informed consent from all participants were obtained. Moreover, this study affected neither the routine diagnosis nor treatment of the lesions presented by the included subjects.

\section{Image acquisition by HD-OCT}

Non-invasive 3-D imaging by HD-OCT (Skintell $^{\circledR}$, AgfaHealthcare, Mortsel, Belgium) has been used to image the internal site of the right upper arm by holding

Fig. 1 Intrinsic age-related morphological parameters imaged by HD-OCD in en face (EF) and cross-sectional (CS) mode. a-c Young women: a small rhomboidal furrow pattern is noticed (magenta arrow). ET (red vertical lines) is $>60 \mu \mathrm{m}$. DEJ is jagged on crosssectional image (green arrow) and papillary rings are regular and small (green circle). DEJ is thickest in young adult (orange line). $\mathbf{d}-$ f Middle aged women: less intersecting furrows are noticed resulting in larger rhomboidal furrow pattern (yellow arrows). ET (red lines) is lesser compared to young adult. More flattening of the DEJ is observed on cross-sectional image (green arrow). Papillary rings are larger and more irregular on en face imaging (green circle). DEJ is thinner compared to young adult. $\mathbf{g}-\mathbf{i}$ Older aged women: a disarranged furrow pattern is observed with some linearization of the furrows (dark green arrows). ET is thinnest in this group (red vertical lines). The DEJ is flat and very thin (green arrow). This results in almost absence of papillary rings on en face image 

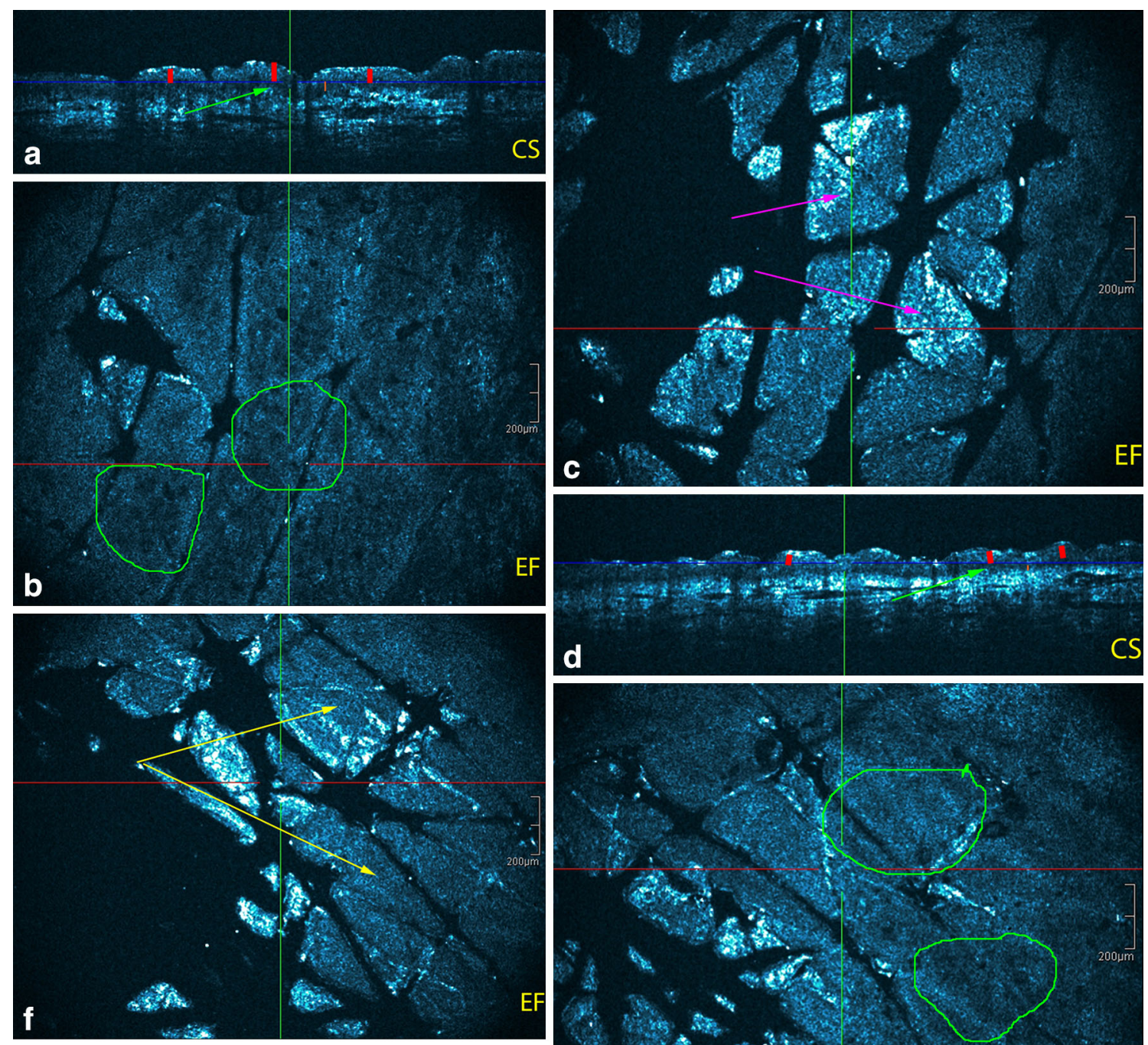

d
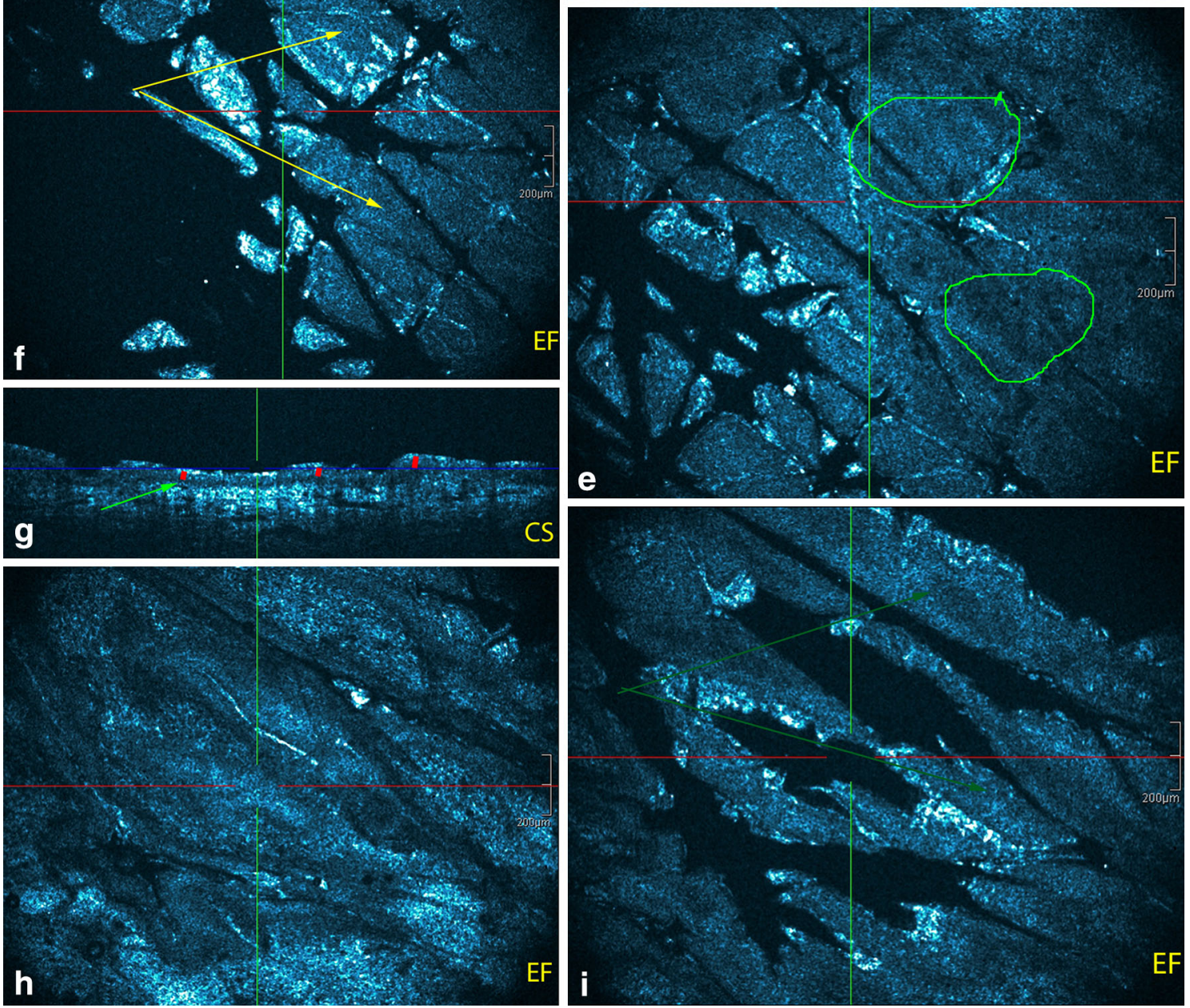
the probe aligned with the axis of the humerus. Instruments and acquisition methods have been previously described [4-9].

\section{Evaluation of IAR morphological HD-OCT features}

All images were evaluated by first author, in blind from any clinical information.

Following Z-levels were scanned: skin surface, dermoepidermal junction (DEJ), upper papillary dermis (up-PD), lower papillary dermis (low-PD) and upper reticular dermis (up-RD). The junction between PD and RD is represented by the highest peak after the valley [33].

\section{Qualitative evaluation}

\section{Standard colour setting (Table 1; Fig. 1)}

1. Furrow patterns have been evaluated as previously described [51]: small rhomboidal, large rhomboidal, linear or disarranged at skin surface on en face images,

2. Flattening (effacement) of DEJ on cross-sectional images and altered ringed pattern of papillary rings on en face images [30]

Inverted colour setting: fibers assessment (Table 2; Figs. 2, 3, 4) Bright structures in the standard colour setting appear dark in the inverted colour setting permitting better assessment of fibers. In addition, collagen fibers cannot be distinguished from elastic fibers by HD-OCT as previously shown [9] (Figs. 2, 3).

1. Thickness of the fibers Thin $(<12 \mu \mathrm{m})$, thick ( $>12$ and $<18 \mu \mathrm{m})$, coarse $(>18 \mu \mathrm{m})$,

2. Length of the fibers Short $(<80 \mu \mathrm{m})$, intermediate (between 80 and $300 \mu \mathrm{m})$ and long $(>300 \mu \mathrm{m}$ ),

3. Morphology of the fibers Curled, wavy, curved or straight rope-like.

4. Organisation of the fibers Loosely interwoven, aggregating in lace-like network (PD) or in randomly "feltwork" (RD), aligned in few or in one direction(s).

5. Clusters of dark dots (a) Dispersed, aligned with fibers or lining hyporeflective holes in vertical orientation ("Candle stick holder"-distribution) (b) increased density (condensed) with horizontal orientation or (c) compact blotches.

Inverted colour setting: dermal microvasculature assessment at two levels: capillary bed in the PD and sub-papillary vascular plexus in $R D$ The inverted colour setting permitted better assessment of microvasculature. The cutaneous microvasculature presented as hyporeflective spaces (Figs. 3, 4).
1. Capillary density in PD High, intermediate or low

2. Morphology of hyporeflective spaces in PD Large ovoid, small ovoid or small round "pinholes"

3. Morphology of hyporeflective spaces in upper RD Small elongated in horizontal plane, large elongated in horizontal plane or prominent and branched vessels with hyperreflective cuff.

\section{Quantitative evaluation}

Backscattered intensity assessment of 3-D HD-OCT DICOM (digital imaging and communication in medicine) images was achieved by using the plugin plot $z$-axis profile of Image $\mathbf{J}^{\circledR}$ software. This is an open source image processing program designed for scientific multidimensional images. The procedure is explained in Fig. 5.

The quantitative evaluation included compaction (measured on the $x$-axis: from 0 to $570 \mu \mathrm{m}$ axial position or depth) and evaluation of backscattered intensity "brightness" (measured on the $y$-axis from 0 to 800 arbitral units (AU). (see Fig. 6 for details). In addition the depth of visibility of fibers in RD was measured. The junction between PD and $\mathrm{RD}$ is represented by the highest peak after the valley [33].

\section{Statistical analysis}

One-way analysis of variance (ANOVA) was used to compare means of three samples using the $\mathrm{F}$ distribution. Moreover, Scheffé test was used for all pairwise comparisons. Calculations were made by using MedCalc ${ }^{\circledR}$ statistical software version 14.12.0.

All dichotomous variables describing the presence/absence of particular HD-OCT features of skin ageing were included. Absolute and relative frequencies were calculated for different age groups. Chi-squared $\left(\chi^{2}\right)$ test was employed to compare each age group versus the other age groups. The phi $(\varphi)$ coefficient, employed to weight diagnostic power of each significant parameter, is a measure of association of two binary variables and is related to the Chi-squared $\left(\chi^{2}\right)$ statistic by the formula: $\varphi^{2}=\chi^{2} / n$, where $n$ equals the total number of observations.

\section{Results}

\section{Subjects}

Sixty, fair-skinned, healthy females were analysed retrospectively for this study. The patients belonged to three age groups: 20 in group I aged 20-39 (Young-Aged: YA), 20 in group II aged 40-59 (Middle-Aged: MA) and 20 in group III aged 60-79 (Older-Aged: OA). 
Table 2 Absolute and relative frequencies of intrinsic skin ageing related morphological features of dermal matrix fibers and dermal microvasculature imaged by 3-D HD-OCT in inverted colour setting

\begin{tabular}{|c|c|c|c|}
\hline & $\begin{array}{l}\text { Young-aged group } \\
(N=20)\end{array}$ & $\begin{array}{l}\text { Middle-aged group } \\
(N=20)\end{array}$ & $\begin{array}{l}\text { Old-aged group } \\
(N=20)\end{array}$ \\
\hline \multicolumn{4}{|l|}{ Dermal matrix fibers } \\
\hline \multicolumn{4}{|l|}{ Morphology } \\
\hline Up-PD: curled thin short fibers & $\begin{array}{l}19(95.0 \%) \\
\quad(p<0.001)^{*}\end{array}$ & $8(40.0 \%)$ & $0(0.0 \%)$ \\
\hline Up-PD: curled thick fibers & $1(5.0 \%)$ & $12(60.0 \%)$ & $\begin{array}{l}20(100.0 \%) \\
\quad(p<0.01)\end{array}$ \\
\hline Low-PD: thick, intermediate wavy fibers & $\begin{aligned} & 19(95.0 \%) \\
&(p<0.001)\end{aligned}$ & $6(30.0 \%)$ & $0(0.0 \%)$ \\
\hline Low-PD: thick straight fibers & $1(5.0 \%)$ & $14(70.0 \%)$ & $\begin{array}{l}20(100.0 \%) \\
\quad(p<0.01)\end{array}$ \\
\hline Up-RD: coarse intermediate curved rope-like bundles of fibers & $\begin{aligned} & 18(90.0 \%) \\
&(\mathrm{p}<0.001)\end{aligned}$ & $7(35.0 \%)$ & $0(0.0 \%)$ \\
\hline Up-RD: coarse intermediate/long straight rope-like bundles of fibers & $2(10.0 \%)$ & $13(65.0 \%)$ & $\begin{array}{l}20(100.0 \%) \\
\quad(p<0.01)\end{array}$ \\
\hline \multicolumn{4}{|l|}{ Organisation of fibers } \\
\hline Up-PD: short fibers loosely interwoven & $\begin{aligned} & 19(95.0 \%) \\
&(p<0.001)\end{aligned}$ & $6(30.0 \%)$ & $0(0.0 \%)$ \\
\hline Up-PD: fibers aggregating in lace-like network & $1(5.0 \%)$ & $14(70.0 \%)$ & $\begin{array}{l}20(100.0 \%) \\
\quad(p<0.01)\end{array}$ \\
\hline Low-PD - Up-RD: fibers in randomly "feltwork" & $\begin{array}{l}19(95.0 \%) \\
\quad(p<0.001)\end{array}$ & $5(15.0 \%)$ & $0(0.0 \%)$ \\
\hline Low-PD - Up-RD: intermediate fibers aligned in few directions & $1(5.0 \%)$ & $\begin{array}{r}13(75.0 \%) \\
(p<0.01)\end{array}$ & $6(30.0 \%)$ \\
\hline $\begin{array}{l}\text { Low-PD - Up-RD: long fibers aligned in one direction corresponding with furrow } \\
\text { pattern }\end{array}$ & $0(0.0 \%)$ & $2(10.0 \%)$ & $\begin{array}{r}14(70.0 \%) \\
(p<0.01)\end{array}$ \\
\hline \multicolumn{4}{|l|}{ Clusters of dots in papillary dermis } \\
\hline $\begin{array}{l}\text { Dispersed aligned with fibers or lining hyporeflective holes in vertical orientation } \\
\text { "Candle stick holder" }\end{array}$ & $\begin{aligned} & 19(95.0 \%) \\
&(p<0.001)\end{aligned}$ & $4(20.0 \%)$ & $0(0.0 \%)$ \\
\hline Increased density (horizontal orientation-condensed) & $1(5.0 \%)$ & $\begin{array}{l}16(80.0 \%) \\
\quad(\mathrm{p}<0.001)\end{array}$ & $2(10.0 \%)$ \\
\hline Compact blotches & $0(0.0 \%)$ & $0(0.0 \%)$ & $\begin{aligned} & 18(90.0 \%) \\
&(p<0.001)\end{aligned}$ \\
\hline \multicolumn{4}{|l|}{ Blood vessels (hyporeflective spaces) } \\
\hline \multicolumn{4}{|l|}{ Capillary density in papillary dermis } \\
\hline High & $\begin{array}{l}19(95.0 \%) \\
\quad(p<0.001)\end{array}$ & $2(10.0 \%)$ & $0(0.0 \%)$ \\
\hline Intermediate & $1(5.0 \%)$ & $\begin{array}{l}17(85.0 \%) \\
\quad(p<0.001)\end{array}$ & $2(10.0 \%)$ \\
\hline Low & $0(0.0 \%)$ & $1(5.0 \%)$ & $\begin{array}{l}18(90.0 \%) \\
\quad(p<0.001)\end{array}$ \\
\hline \multicolumn{4}{|l|}{ Vessel morphology in papillary dermis } \\
\hline Large ovoid & $\begin{aligned} & 19(95.0 \%) \\
&(p<0.001)\end{aligned}$ & $3(15.0 \%)$ & $0(0.0 \%)$ \\
\hline Small ovoid & $1(5.0 \%)$ & $\begin{array}{l}16(80.0 \%) \\
\quad(p<0.001)\end{array}$ & $1(5.0 \%)$ \\
\hline Small round "pinholes" & $0(0.0 \%)$ & $1(5.0 \%)$ & $\begin{array}{l}19(95.0 \%) \\
\quad(p<0.001)\end{array}$ \\
\hline \multicolumn{4}{|l|}{ Vessel morphology in reticular dermis } \\
\hline Small elongated in horizontal plane & $\begin{array}{l}19(95.0 \%) \\
\quad(p<0.001)\end{array}$ & $2(10.0 \%)$ & $0(0.0 \%)$ \\
\hline Large elongated in horizontal plane & $1(5.0 \%)$ & $\begin{array}{l}18(90.0 \%) \\
\quad(p<0.001)\end{array}$ & $2(10.0 \%)$ \\
\hline Prominent and branched vessels with hyper-reflective cuff & $0(0.0 \%)$ & $0(0.0 \%)$ & $\begin{array}{l}18(90.0 \%) \\
\quad(p<0.001)\end{array}$ \\
\hline
\end{tabular}

$\mathrm{p}$ values in italic are significant if $p<0.05$

$U p-P D$ upper papillary dermis, $L o w-P D$ lower papillary dermis, $U p-R D$ upper reticular dermis

* $p$ values have been added whenever appropriate; for details see "Results" 


\section{Qualitative evaluation of IAR morphological HD- OCT features}

\author{
Standard colour setting (Table 1; Fig. 1)
}

The furrow pattern at skin surface on en face images differed according to age Small rhomboidal furrow pattern was a sensitive (SS) and specific (SP) feature of YA-group $\left(95 \%\right.$ and $97.5 \%$, respectively; $\varphi=0.93, \chi^{2}=51.34$, $p<0.001)$. Large rhomboidal pattern and linear furrow patterns were co-dominant in the MA-group with moderate sensitivity but high specificity (large rhomboidal: $55 \%$ SS and $97.5 \%$ SP; $\varphi=0.62, \chi^{2}=22.97, p<0.001$ and linear furrow: $35 \% \mathrm{SS}$ and $87.5 \% \mathrm{SP} ; \varphi=0.27$, $\left.\chi^{2}=0.47, \mathrm{NS}\right)$. A disarranged furrow pattern was a sensitive and specific feature for the OA-group (70 and $97.5 \%$, respectively; $\left.\varphi=0.73, \chi^{2}=32.4, p<0.001\right)$. A large rhomboidal and linear pattern was also observed in the OA group in $1 / 20$ and $5 / 20$ cases, respectively.

Flattening of DEJ on cross-sectional images vs papillary ring on en face images Flattening of DEJ was a highly sensitive and specific feature of the OA-group (99.5\% SS and $87.5 \%$ SP; $\left.\varphi=0.83, \chi^{2}=41.57, p<0.001\right)$. A jagged subepidermal dark band was highly sensitive but moderately specific for the YA-group $(99.5 \% \mathrm{SS}$ and $62.5 \%$ SP; $\left.\varphi=0.59, \chi^{2}=21.06, p<0.01\right)$. Follicular structures could interrupt these images. However, on the corresponding en face images age-related alterations of papillary rings were observed: small regular rings in YA $\left(99.5 \% \mathrm{SS}\right.$ and $62.5 \%$ SP; $\varphi=0.59, \chi^{2}=21.6$, $p<0.01)$, larger irregular rings in MA $(50 \% \mathrm{SS}$ and $97.5 \%$ SP; $\left.\varphi=0.58, \chi^{2}=20.09, p<0.01\right)$ and absence of rings in OA-group (99.5\% SS and $87.5 \% \mathrm{SP}$; $\left.\varphi=0.83, \chi^{2}=41.57, p<0.001\right)$.

\section{Inverted colour setting (Table 2; Figs. 2, 3, 4)}

Morphology of fibers Papillary dermis In the upper part of PD (Fig. 2) the presence of curled thin short fibers was a highly sensitive (95\%) and specific (80\%) feature of YAskin $\left(\varphi=0.71, \chi^{2}=30.30, p<0.001\right)$. Thick curled fibers were highly sensitive $(99.5 \%)$ but moderately specific $(67.5 \%)$ for OA-skin $\left(\varphi=0.63, \chi^{2}=24.17\right.$, $p<0.01)$. Both types of fibers were present in MA-skin in $8 / 20(40 \%)$ and $12 / 20(60 \%)$ cases, respectively. In the lower part of PD (Fig. 3) the presence of thick, intermediate wavy fibers was highly sensitive $(95 \%)$ and specific $(85 \%)$ of YA-skin $\left(\varphi=0.76, \chi^{2}=35.11, p<0.001\right)$. Thick straight fibers were highly sensitive $(99.5 \%)$ but moderately specific $(62.5 \%)$ for OA-skin $(\varphi=0.59$, $\left.\chi^{2}=21.06, p<0.01\right)$. Both types of fibers were present in
Fig. 2 HD-OCT dermal ultrastructural and microvascular features of PD in women of three different age groups. Young women: a crosssectional image with dark blue horizontal line indicating the $Z$ value of the en face image. b Same cross-sectional image with epidermis edging (orange lines). Left side of the blue line is still corresponding to DEJ while right side of the blue line is already corresponding to the PD. c Corresponding en face image. Left side displays the DEJ and some artefacts (magenta arrows). Right side displays the superficial part of the PD. Thin, short and curled fibers form a randomly oriented feltwork (green circles). Disperse black dots align with these fibers (light blue arrow). Clusters of black dots (yellow circles) are noticed around the capillary loops (green arrows). The capillary bed of PD present as numerous homogenous distributed small round hyporeflective spaces (green arrows). Candle stick holder configuration of black dots is encircled in yellow on cross-sectional image. Middle aged women: $\mathbf{d}$ cross-sectional imaging with dark blue horizontal line indicating the $Z$ value of the en face image. e Same cross-sectional image with epidermis edging (orange lines). Left side of the blue line is still corresponding to the DEJ. Right side of the blue line is already indicating the PD. The ET is thinner than in young adults. f Corresponding en face image. $2 / 3$ of left side displays the DEJ with one artefact (magenta arrow). Right side displays the superficial part of the PD. Fibers are thicker, longer and straighter compared to young adults. Moreover, they become more aggregated and aligned in few directions (green circles). Disperse black dots condensed but still aligned with fibers (light blue arrows). Clusters of black dots increase in density and are progressively oriented in a more horizontal way (thin yellow circle on cross-sectional image). A reduction of the capillary area is observed (green arrows). Older aged women: g cross-sectional image with dark blue line indicating the $Z$ value of the en face image. h Same cross-sectional image with epidermis edging (orange lines). At the left side of the image the blue line corresponds with lower PD while at the right side of the image blue line corresponds with middle part of PD. Epidermal thickness is thinner than in middle aged adults. i Fibers become more and more aggregated in a lace-like network (green circle). Clusters of black dots merge to form compact dark blotches. A further reduction of the density of the capillary bed (green arrows) is noticed resulting in an increase in lower capillary density. The top of the image corresponds with the upper part of the reticular dermis displaying a prominent subpapillary plexus (magenta circle)

MA-skin in 6/20 (30 \%) and 14/20 (70 \%) cases, respectively. Superficial reticular dermis. Coarse intermediate curved rope-like bundles of fibers are $90 \%$ sensitive and $82.5 \%$ specific for YA-skin $\left(\varphi=0.69, \chi^{2}=28.83\right.$, $p<0.001)$. Coarse long straight rope-like bundles of fibers were highly sensitive $(99.5 \%)$ but poorly specific $(62.5 \%)$ for OA-skin $\left(\varphi=0.59, \chi^{2}=20.68, p<0.01\right)$. Both bundles of fibers could be observed in MA, in 7/20 (35\%) and 13/20 (75 \%) cases, respectively (Fig. 4).

Organisation of fibers Upper papillary dermis (Fig. 2). The presence of short loosely interwoven fibers was a highly sensitive $(95 \%)$ and specific $(85 \%)$ feature of YAskin $\left(\varphi=0.76, \chi^{2}=35.11, p<0.001\right)$. Fibers aggregating in a lace-like network were highly sensitive $(99.5 \%)$ but poorly specific $(62.5 \%)$ for OA-skin $(\varphi=0.59$, $\left.\chi^{2}=21.06, p<0.01\right)$. Both organizations were also observed in MA-skin, in 6/20 (30\%) and 14/20 (70\%) 

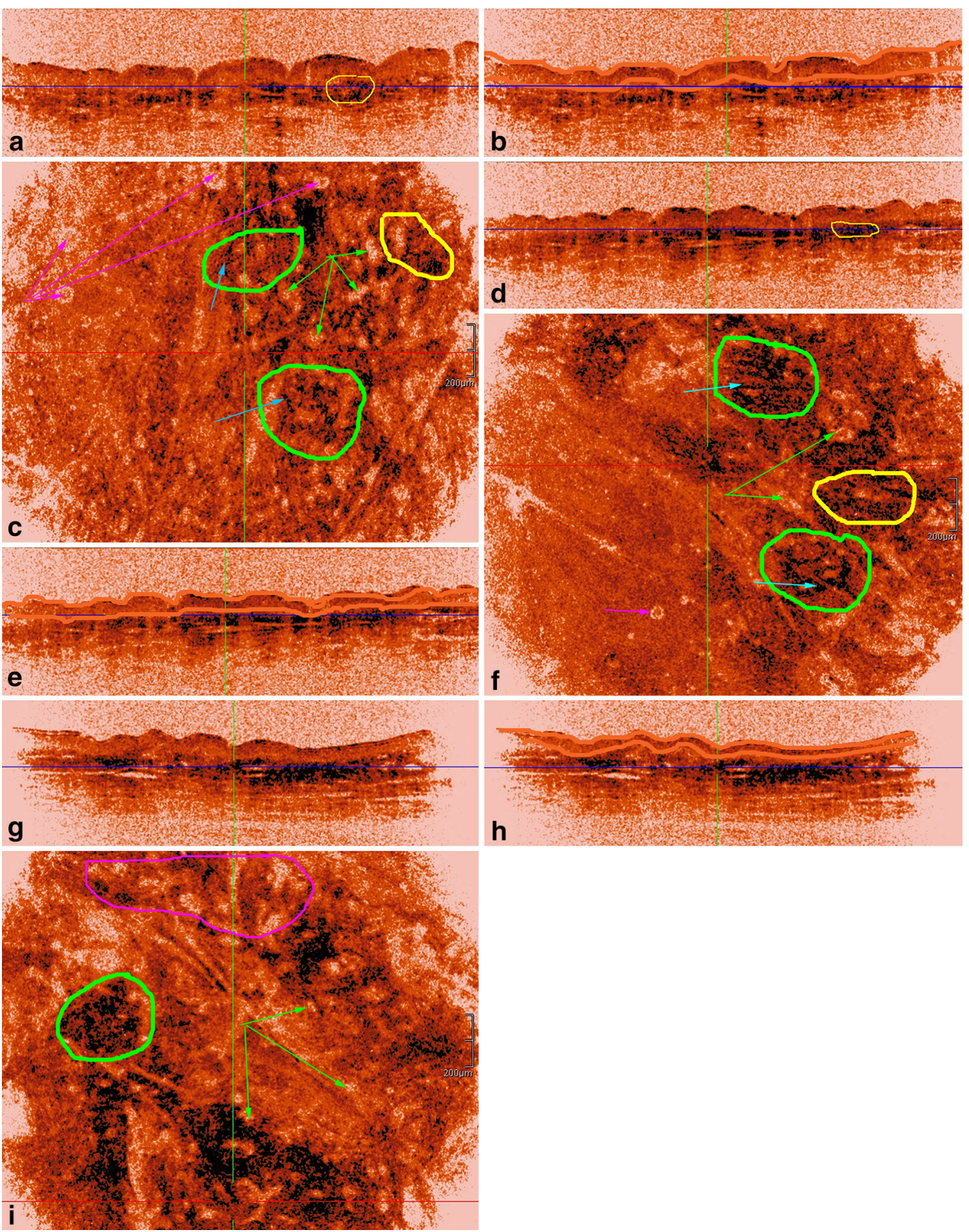

cases, respectively. Lower papillary dermis (Fig. 3)—upper reticular dermis (Fig. 4). Fibers organized randomly in "feltwork" was a dominant feature of YA-skin $(95 \%$ SS, $87.5 \%$ SP; $\left.\varphi=0.79, \chi^{2}=37.81, p<0.001\right)$. Intermediate long fibers aligned in few directions were predominantly observed in MA-skin although with low sensitivity (65\%) and moderate specificity $(82.5 \%)\left(\varphi=0.48, \chi^{2}=13.54\right.$, $p<0.01)$. Moreover, this fibre organization was noticed in $1 / 20(5 \%)$ YA-skin and 6/20 (30\%) cases of OA-skin. Long fibers aligned in one direction corresponding to furrow pattern were predominantly observed in OA-skin with moderate sensitivity $(70 \%)$ and specificity $(76 \%)(\varphi=$ $\left.0.62, \chi^{2}=23.05, p<0.01\right)$. This kind of fibre organization was absent in YA-skin and present in 2/20 (10 \%) MA-skin. 
Clusters of dots in PD Dispersed dots aligned with fibers or lining hyporeflective holes in a vertical orientation (candle stick holder orientation) were found with high sensitivity $(95 \%)$ and specificity $(90 \%)$ in YA-skin $\left(\varphi=0.82, \quad \chi^{2}=40.75, \quad p<0.001\right)$. In MA-skin an increased density of dots aligned in a more horizontal orientation was observed with moderate sensitivity (80\%) but high specificity $(92.3 \%) \quad\left(\varphi=0.73, \chi^{2}=32.2\right.$, $p<0.001)$. Compact blotches were exclusively observed in OA-skin (90\% SS, $99.8 \% \mathrm{SP} ; \varphi=0.92, \chi^{2}=50.98$, $p<0.001)$.

Dermal microvasculature Features of the dermal microvasculature were assessed both at the PD and RD (Table 3; Figs. 3, 4).

1. Capillary density in PD A high capillary density was predominantly observed in YA-skin (95\% SS, $95 \%$ SP; $\left.\varphi=0.89, \chi^{2}=47.47, p<0.001\right)$. Low capillary density was a highly sensitive and specific feature in OA-skin (90\% SS, $97.5 \% \mathrm{SP} ; \varphi=0.89, \chi^{2}=47.18$, $p<0.001)$. In MA-skin an intermediate capillary density was found $(85 \% \mathrm{SS}, 92.5 \% \mathrm{SP} ; \varphi=0.78$, $\left.\chi^{2}=36.04, p<0.001\right)$.

2. Vessel morphology in PD The presence of large ovoid hyporeflective spaces was a sensitive (95\%) and specific $(87.5 \%)$ feature for YA-skin $(\varphi=0.79$, $\left.\chi^{2}=37.81, p<0.001\right)$. Small ovoid hyporeflective spaces were observed in 16/20 (80\%) cases of MAskin $\left(\varphi=0.77, \chi^{2}=35.71, p<0.001\right)$, and only $1 / 20(5 \%)$ case of YA-skin and 1/20 (5\%) case of OA-skin. The presence of small pinhole hyporeflective spaces was a sensitive $(95 \%)$ and specific $(97.5 \%)$ feature of OA-skin $\left(\varphi=0.93, \chi^{2}=51.34\right.$, $p<0.001)$.

3. Vessel morphology in $R D$ Elongated vessels in horizontal plane were present in 19/20 cases of YA-skin (95\% SS, $95 \%$ SP; $\left.\varphi=0.89, \chi^{2}=47.18, p<0.001\right)$. Larger elongated vessels in horizontal plane were present in 18/20 cases of MA-skin (90\% SS, $92.5 \%$ SP; $\left.\varphi=0.89, \chi^{2}=47.18, p<0.001\right)$. Prominent and branched vessels with hyper-reflective cuff were exclusively observed in OA-skins (18/20 cases: $90 \% \mathrm{SS}$, 99.8 \% SP; $\left.\varphi=0.89, \chi^{2}=47.18, p<0.001\right)$.

\section{Quantitative evaluation of IAR changes in compaction and brightness (backscattered intensity) of different skin layers (Figs. 5, 6; Table 3)}

1. Epidermis A significant difference $(p<0.001)$ in compaction of the epidermis could be observed between the three groups. This compaction increased
Fig. 3 HD-OCT dermal ultrastructural and microvascular features at the junction of papillary and reticular dermis in women of three different age groups. Young women: a cross-sectional image with dark blue horizontal line indicating the $Z$ value of the en face image. Short black line with $Z$ value just under basal cell layer. The thickness of the PD is shown by a double yellow arrow. The sub-papillary plexus corresponds with larger, elongated and horizontal oriented hyporeflective spaces (green arrows). b Corresponding en face image displays a randomly oriented network of coarse, long, curved but discrete rope-like bundles of fibers (green circle). Disperse black dots align with these fibers (light blue arrow). Clusters of black dots are sparse. The sub-papillary plexus corresponds with larger, elongated and horizontal oriented hyporeflective spaces. (green arrows). Middle aged women: c cross-sectional image with dark blue horizontal line indicating the $Z$ value of the en face image. Short black line with $Z$ value just under the basal cell layer. The thickness of the PD is indicated by a double yellow arrow. The papillary thickness is smaller compared to young adults. d Corresponding en face image. Fibers are thicker, longer and straighter compared to young adults. They form more marked rope-like bundles of fibers (green circle). Moreover, they become more aggregated and aligned in few directions corresponding with furrow pattern (dark green lines). Disperse black dots condensed but still aligned with fibers (light blue arrows). Clusters of black dots increase in density and are progressively oriented in a more horizontal way (light blue arrow). The subpapillary plexus corresponds with larger, elongated and horizontal oriented hyporeflective spaces. (green arrows). Older aged women: e cross-sectional image with dark blue horizontal line indicating the $Z$ value of the en face image. Short black line with $Z$ value just under the basal cell layer. The thickness of the PD is indicated by a double yellow arrow. The papillary thickness is smallest. $\mathbf{f}$ Corresponding en face image. Straight rope-like bundles of fibers (green circle) aggregate and align in one main direction corresponding with the furrow pattern (dark green lines). The Clusters of black dots merge to form compact dark blotches. The sub-papillary plexus becomes very prominent with strongly dilated horizontal oriented elongated branching hyporeflective spaces (green arrows)

progressively with age. Regarding the brightness of epidermis a significant $(p<0.001)$ increase could be observed in OA group compared to the other two groups.

2. Dermo-epidermal junction A significant increase $(p<0.001)$ in compaction and brightness of the DEJ was observed with age.

3. Papillary dermis An age-related significant $(p<$ 0.001 ) increase in compaction and brightness of the papillary dermis was noticed.

4. Reticular dermis The depth of visibility of fibers in deeper layers of reticular dermis increased significantly $(p<0.001)$ with age.

\section{Discussion}

In this study we presented morphological features of sunprotected skin visualized in 3-D by HD-OCT in women belonging to three different age groups.

The terminology and study design of the in vivo confocal microscopy studies $[30,51]$ dealing with skin 

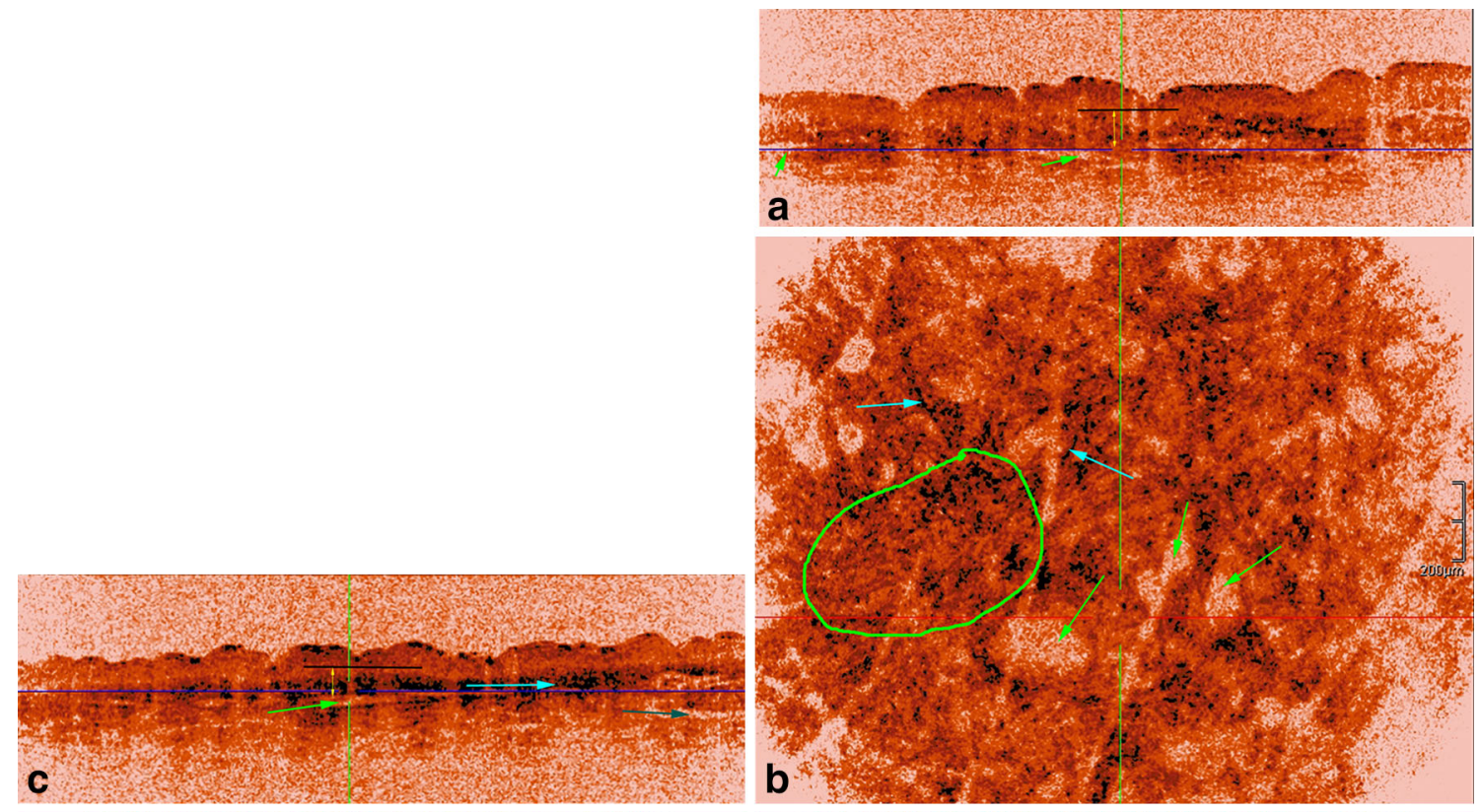

a
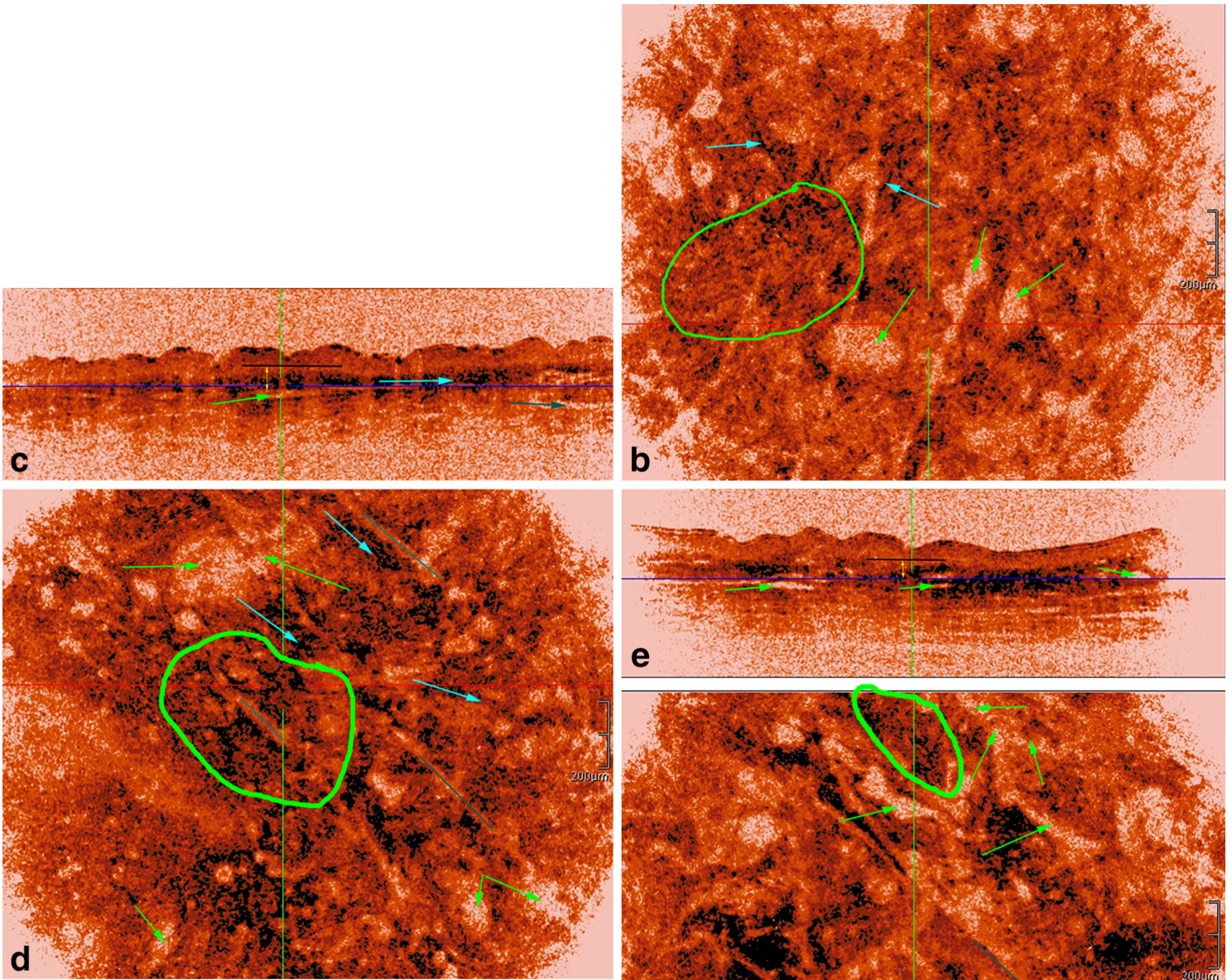

e

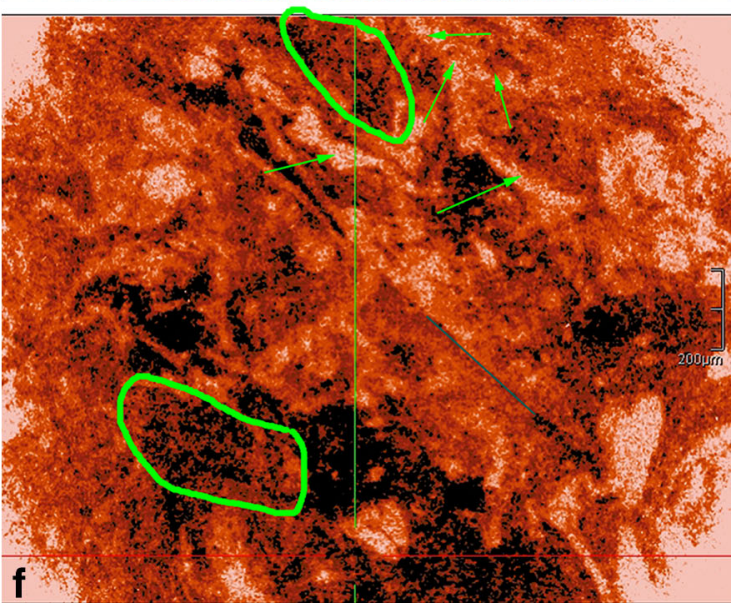

ageing related morphological changes of epidermis and superficial dermis have been adapted to the HD-OCT. A new terminology and adjusted study design have been proposed regarding morphological assessment of fibers in both papillary and superficial reticular dermis as well as dermal microvasculature in inverted colour setting. Moreover, the present study offers for the first time a quantitative evaluation of HD-OCT descriptors for intrinsic skin ageing based on backscattered intensity measurements.

HD-OCT enables imaging of IAR qualitative skin changes. HD-OCT permits the visualization of the surface texture and furrow pattern in one single en face image because of the large field of view $(1.8 \times 1.5 \mathrm{~mm})$. This paper suggests that loss of intersecting furrows in sunprotected skin sites is a chronological process, not necessarily linked to sun damage. These findings are in line with previous studies regarding RCM and skin surface topography $[1,30,51]$.

With intrinsic ageing, the flattening of the DEJ on crosssectional HD-OCT imaging is more pronounced. The higher axial resolution $(3 \mu \mathrm{m})$ of HD-OCT probably enables a better visualization of the DEJ compared to other non-invasive technologies with cross-sectional imaging such as HF-US and conventional OCT. According to Lavker et al. the major change in ageing skin is the 


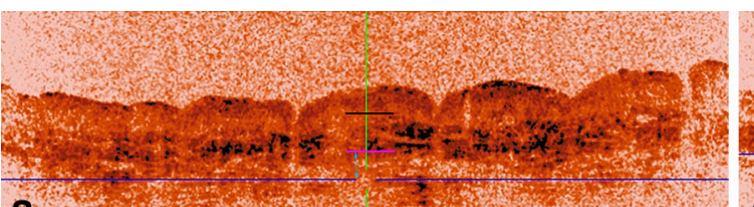

a
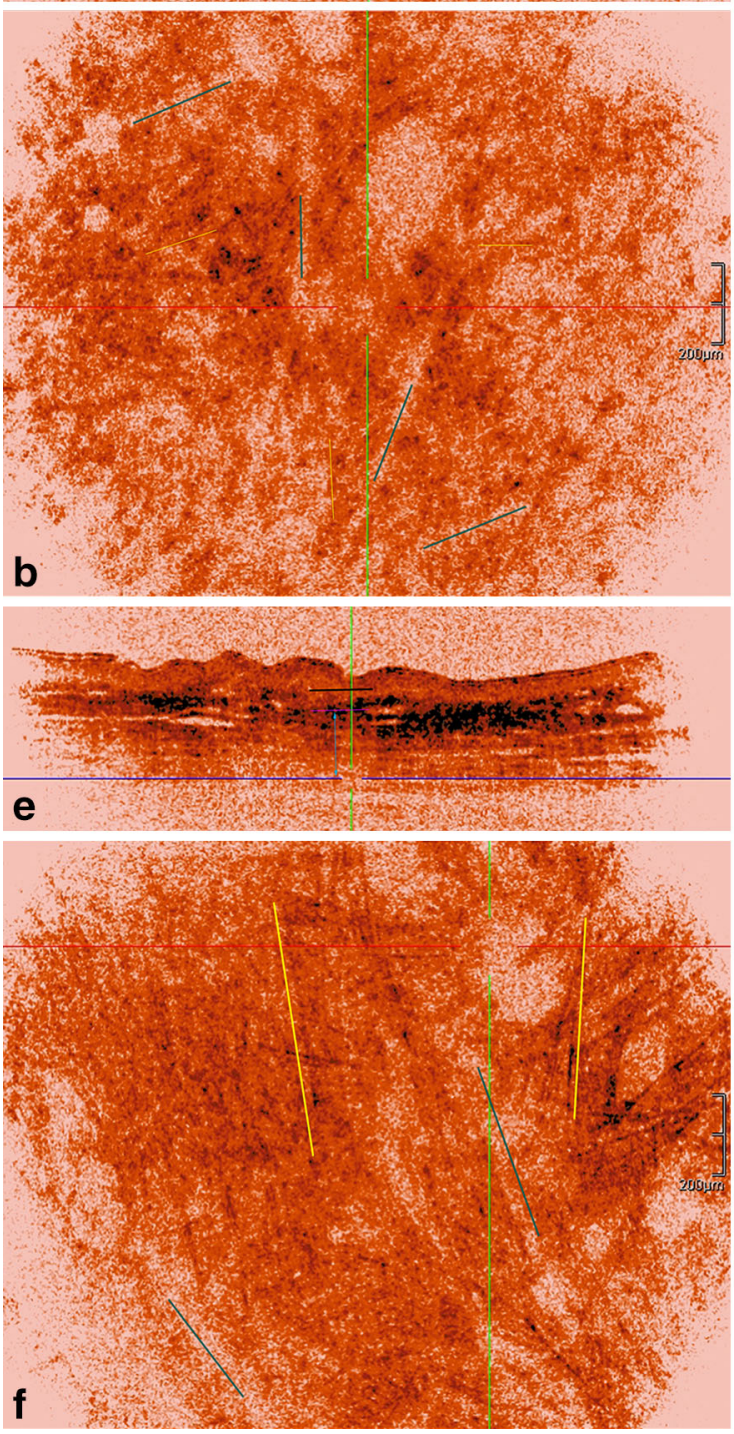

Fig. 4 HD-OCT imaging of dermal fibers deeper in reticular dermis in women of three different age groups. Young women: a crosssectional image with dark blue horizontal line indicating the $Z$ value of the en face image. Short black line with $Z$ value just under basal cell layer. Short magenta line with $Z$ value corresponding with junction of papillary and reticular dermis. Fibers are still visible up to a depth of $80 \mu \mathrm{m}$ under the junction of papillary and reticular dermis (light blue double arrow). b Corresponding en face image displays a randomly oriented network of discrete rope-like bundles of fibers (yellow lines). Furrow lines are displayed (green lines). Middle aged women: c cross-sectional image with dark blue horizontal line indicating the $Z$ value of the en face image. Short black line with $Z$ value just under basal cell layer. Short magenta line with $Z$ value corresponding with junction of papillary and reticular dermis. Fibers

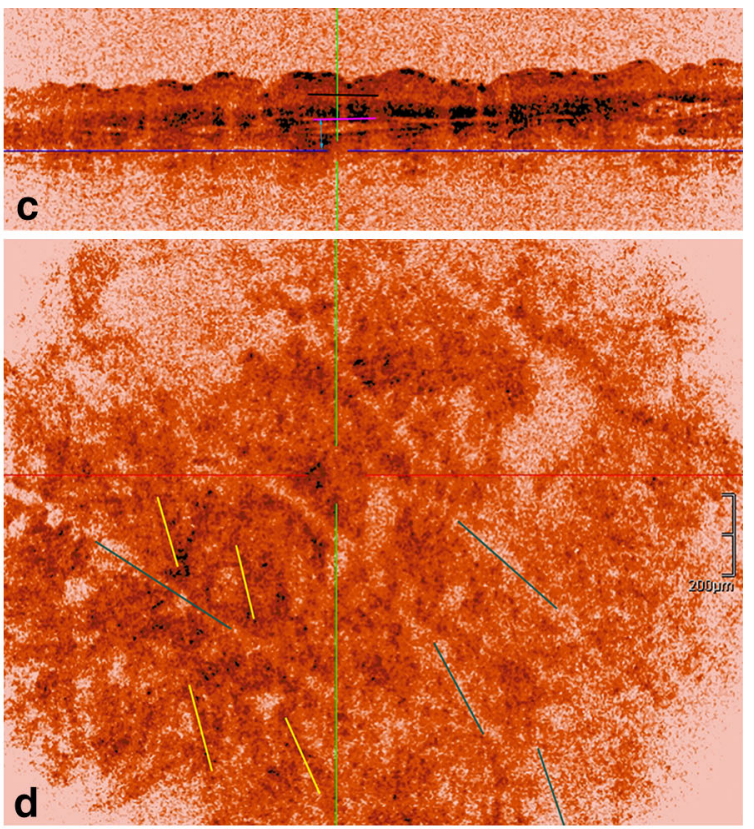

are still visible up to a depth of $65 \mu \mathrm{m}$ under the junction of papillary and reticular dermis (light blue double arrow). d Corresponding en face image. Fibers form marked rope-like bundles. They become more aggregated and aligned in few directions corresponding with furrow pattern (dark green lines). Older aged women: e crosssectional image with dark blue horizontal line indicating the $Z$ value of the en face image. Short black line with $Z$ value just under basal cell layer. Short magenta line with $Z$ value corresponding with junction of papillary and reticular dermis. Fibers are still visible up to a depth of $185 \mu \mathrm{m}$ under the junction of papillary and reticular dermis (light blue double arrow). f Corresponding en face image. Straight rope-like bundles (yellow lines) align in almost one direction. This predominant direction corresponds with the linear furrow pattern (green dark lines). Very long fibers $(>400 \mu \mathrm{m})$ are observed 


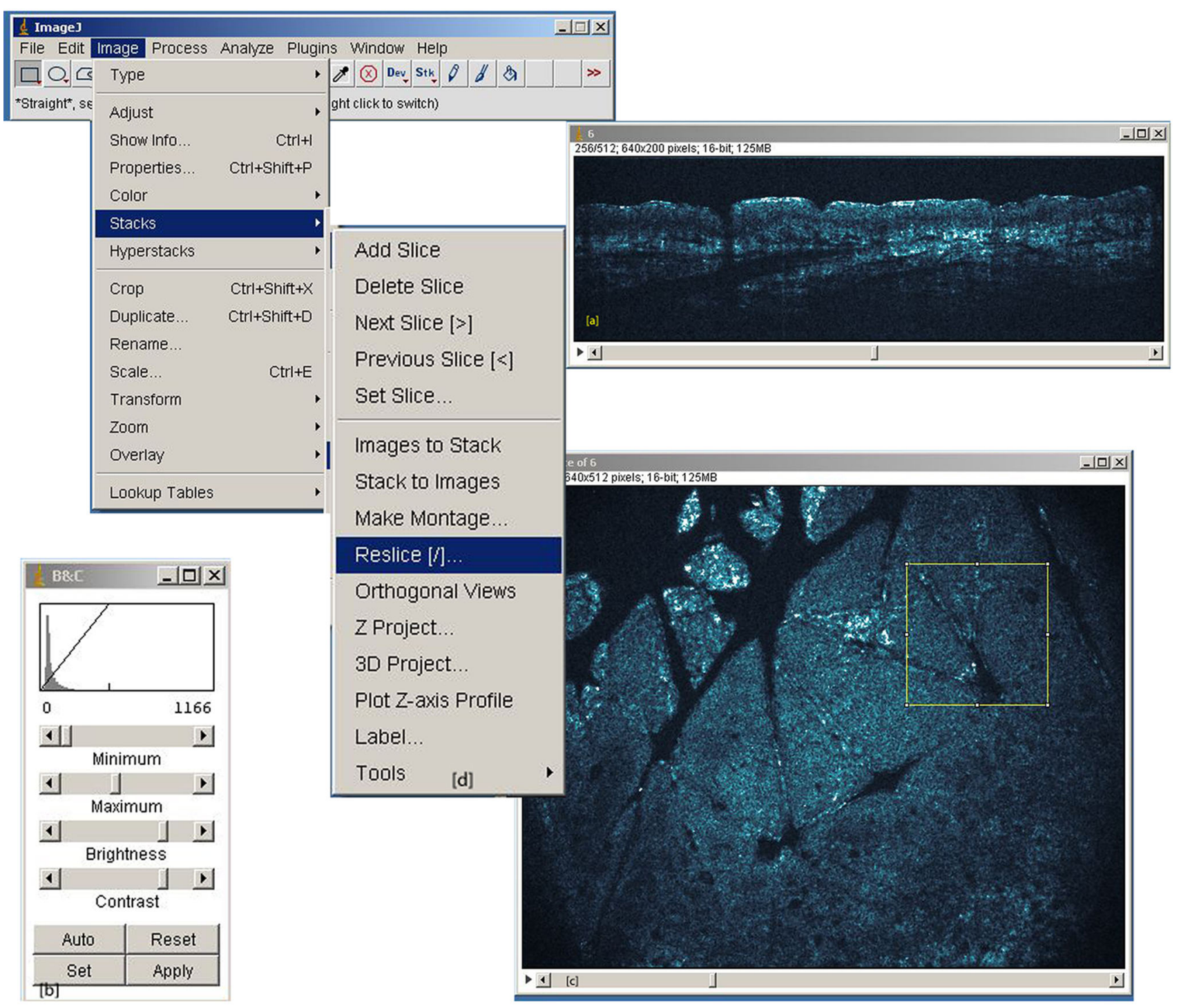

Fig. 5 Plugin plot $z$-axis profile of Image ${ }^{\circledR}$ software analysis of 3-D HD-OCT DICOM images. Procedure is as follows, a 3-D Dicom image (128 MB) of interest is selected and file opened as crosssectional view. b Correction for brightness and contrast (minimum " 0 " and maximum value is chosen between "1150 and 1200"). c Image $>$ Stack $>$ Reslice of image in order to open the

flattening of the DEJ because of retraction of the epidermal down-growths in combination with a loss in proliferative capacity associated with the aged epidermis [26]. Age-related functional and structural changes in human DEJ components have been described [27]. The flattening of the DEJ on HD-OCT cross-sectional images corresponds with irregular papillary rings up to the complete disappearance of these rings on en face images. These findings are in line with previous RCM observations by Longo and Wurm et al. [30, 51].

In contrast to MTP [23, 24, 38], collagen fibers cannot be distinguished from elastic fibers by HD-OCT [9]. corresponding en face image. Four square $(450 \times 450 \mu \mathrm{m})$ regions of interest (ROI) were chosen, one in each quadrant of the horizontal (en face) image. d Image $>$ Stack $>$ plot $z$-axis profile: Intensity (I) of brightness of single VOIs (Volume of interest: scanned volume equals $450 \mu \mathrm{m} \times 450 \mu \mathrm{m} \times 570 \mu \mathrm{m}=0.11 \mathrm{~mm}^{3}$ ) is assessed and values transferred to excel table and displayed in a graphic (Fig. 6)

However, age-related morphological changes of the dermal matrix fibers could be observed with HD-OCT. Moreover, real time 3-D HD-OCT provided volumetric information about the dermal matrix fibers organisation. With intrinsic skin ageing, fibers in PD become thicker, longer, straighter and progressively aggregated in a lace-like network. In the superficial RD these fibers formed IAR straight thick ropelike bundles, no longer oriented randomly but in only in few directions. These findings are in line with evidence for the IAR degradation of fibrous extracellular matrix components including elastin, fibrillin-containing oxytalan fibers and the collagen types I, III and IV [32]. Interestingly 
Table 3 Quantitative evaluation of age-related changes in compaction and backscattered intensity (brightness)

\begin{tabular}{llll}
\hline Feature & Young aged group & Middle aged group & Old aged group \\
\hline Compaction of epidermis $(\mu \mathrm{m}) \Delta_{\mathrm{EP}}$ & $64.5[ \pm 3.03](p<0.001) *$ & $43.5[ \pm 2.02](p<0.001)$ & $33.75[ \pm 1.43](p<0.001)$ \\
Compaction of DEJ (Degrees $\left.{ }^{\circ}\right) \Delta_{\mathrm{DEJ}}$ & $63.8[ \pm 1.96]$ & $60.2[ \pm 2.22]$ & $35.75[ \pm 1.36](p<0.001)$ \\
Compaction of papillary dermis $(\mu \mathrm{m}) \Delta_{\mathrm{PD}}$ & $63.75[ \pm 3.75](p<0.001)$ & $54.75[ \pm 2.51](p<0.001)$ & $30.75[ \pm 1.19](p<0.001)$ \\
Visibility of fibers in deeper reticular dermis $(\mu \mathrm{m})$ & $79.4[ \pm 3.09]$ & $65.15[ \pm 6.94]$ & $175.2[ \pm 12.16](p<0.001)$ \\
$V_{\mathrm{RD}}$ & $140.15[ \pm 8.13]$ & $154.05[ \pm 17.12]$ & $447.45[ \pm 48.08]$ \\
Brightness of epidermis $(\mathrm{AU}) I_{\mathrm{EP}}$ & & & $(p<0.001)$ \\
& $47.5[ \pm 8.09](p<0.001)$ & $77.95[ \pm 10.88](p<0.001)$ & $184.25[ \pm 13.74]$ \\
Brightness of DEJ (AU) $I_{\mathrm{DEJ}}$ & $197.2[ \pm 14.74]$ & $270.05[ \pm 20.67]$ & $(p<0.001)$ \\
Brightness of papillary dermis $(\mathrm{AU}) I_{\mathrm{PD}}$ & $(p<0.001)$ & $(p<0.001)$ & $446.1[ \pm 28.23](p<0.001)$ \\
\end{tabular}

* $p$ values are mentioned whenever appropriate; for details see "Results"

only in OA-skin very long $(>400 \mu \mathrm{m})$, almost unidirectional fibers were imaged by HD-OCT at up to a $185 \mu \mathrm{m}$ depth under the PD/RD junction. Moreover, these fibers were aligned with the linear furrow pattern. This phenomenon probably corresponds to the process of glycation producing crosslinks between macromolecules, which provides an explanation for the increased age-related stiffness of the skin [35]. In PD, dispersed dark dots (imaged in the inverted colour setting mode) aligned with fibers and vessels and become more and more condensed with intrinsic ageing. In young skin, these dark dots had a candlestick-holder-like 3-D configuration as if they were sustaining the dermal papillae. In elderly skin these black dots condensed progressively to form large dark blotches near the flattened DEJ. To the best of our knowledge, these observations have not been described in studies using other in vivo microscopy techniques. Our findings seem to be in agreement with observations made by scanning electron micrography of matrix fibers in young and aged dermis (low resolution mode) [26]. The present study, however, suggests that flattening of the DEJ is related to the disappearance of the support of dermal papillae by the candlestick-holder-like configuration.

IAR morphological changes of the cutaneous microcirculation were observed by HD-OCT. An age-related decrease in number and size of capillary loops in the dermal papillae and an increase in size of the sub-papillary plexus are in line with laser Doppler flowmetry and videocapillaroscopy findings [22, 28, 29, 47]. Interestingly our study described a hyper-reflective cuff around the branched vessels of the sub-papillary plexus in elderly skin.

A quantitative assessment of HD-OCT descriptors for intrinsic skin ageing has been made possible by Image ${ }^{\circledR}$ software analysis of HD-OCT images. A significant progressive compaction of epidermis, DEJ and PD with age could be detected. This compaction paralleled the increase
Fig. 6 Evaluation of compaction (measured on the $x$-axis: from 0 to 200 ; 1 unit $=3 \mu \mathrm{m}$; axial position or depth) and brightness (backscattered intensity) ( $y$-axis from 0 to $800 \mathrm{AU}$ (arbitral units). Compaction of epidermis: $\left(\Delta_{\mathrm{EP}}=\right.$ distance from first peak to the valley's middle point in $\mu \mathrm{m})$ and brightness of epidermis $\left(I_{\mathrm{EP}}=\right.$ difference between first peak and the $200 \mathrm{AU}$ line: under this value only noise could be detected on the original DICOM image). Compaction of DEJ $\left(\Delta_{\mathrm{DEJ}}=\right.$ angle (in degrees) produced by the descendent line of the valley and the ascendant line of the valley) and brightness of DEJ $\left(I_{\mathrm{DEJ}}=\right.$ difference between the bottom of the valley and the $200 \mathrm{AU}$ line). Compaction of $P D\left(\Delta_{\mathrm{PD}}=\right.$ distance from middle of valley to second peak in $\mu \mathrm{m})$ and brightness of $P D\left(I_{\mathrm{PD}}=\right.$ difference between the highest peak after the valley and the 200 AU line). The highest peak after the valley represents the junction between PD and RD [33]). Depth of visibility of fibers in $R D\left(V_{\mathrm{RD}}\right.$ in $\left.\mu \mathrm{m}\right)$ : under the $200 \mathrm{AU}$ line only noise could be detected. a Compaction and brightness in youngaged skin (for discussion see "Results"). b Compaction and brightness in middle-aged skin (for discussion see "Results"). c Compaction and brightness in old aged skin (for discussion see "Results")

in backscattered intensity or brightness of the different layers.

An IAR significant progressive compaction of the epidermal component could be found. In the present study, a new method for epidermal thickness (ET) assessment has been described. In this method stratum corneum thickness was included in the ET measurement. ET measurement by HD-OCT has already been discussed in detail by a recent investigation [8]. In that study, the thickness of the stratum corneum was not included in the overall ET assessment of the skin of the back; moreover, $55 \%$ of the subjects belonged to YA-group and $45 \%$ to MA-group. A mean value for ET at the back was $47.38 \mu \mathrm{m}( \pm 1.07 \mu \mathrm{m} 95 \%$ $\mathrm{CI})$. In the present study, the mean value for ET at the inner site of the upper arm of subjects aged between 20 and 60 years was $54 \mu \mathrm{m}( \pm 3.75 \mu \mathrm{m} 95 \% \mathrm{CI})$. The difference between the means of ET in the two studies could be explained by stratum corneum in-/exclusion and anatomic site. The IAR compaction of the epidermis is in agreement 
Arch Dermatol Res (2015) 307:705-720

717

a
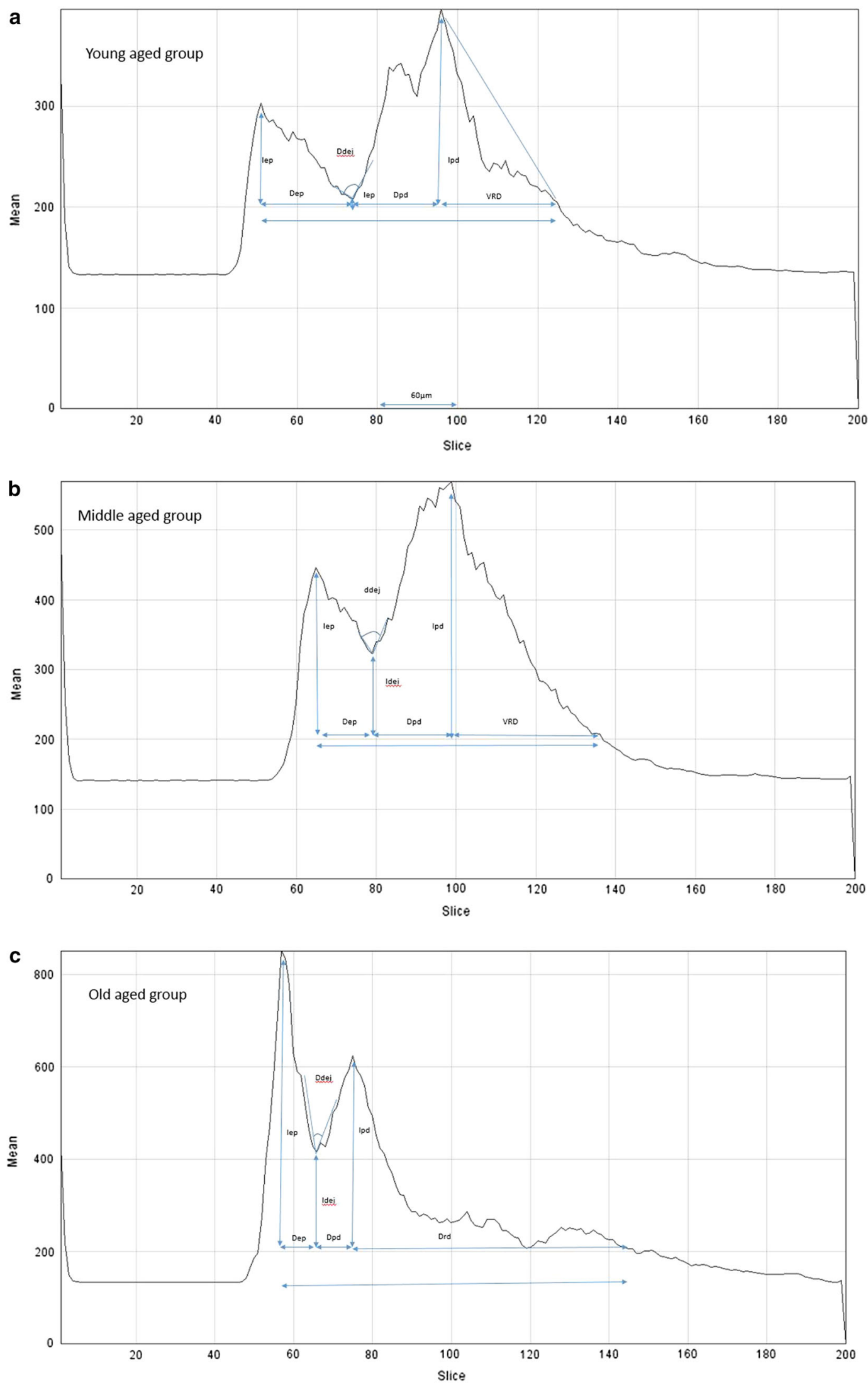

Springer 
with findings by other non-invasive technologies such as RCM [30, 51], MPT [23] and conventional OCT [14]. Interestingly, in the present study a significant increase in epidermal backscattered intensity (brightness) in elderly skin was observed compared to MA- and YA-skin. Skin dryness represents an important characteristic of aged skin. Aquaporin-3 distribution in human epidermis is consistent with epidermal water distribution and parallels the steep water gradient at the junction between stratum granulosum and stratum corneum [3]. A significant decrease of aquaporin 3 (AQP-3) expression in the epidermis with chronological ageing has been described [45] probably explaining the significant increase in epidermal brightness of HD-OCT images with age.

A significant increase in compaction and brightness of the DEJ with chronological age was noticed with HD-OCT. This is in agreement with the IAR degradation of fibrous extracellular matrix components and with the loss of the oligosaccharide fraction which in turn impacts on the ability of tissue to retain bound water [27, 32]. A decreased DEJ thickness with age has already been described for conventional OCT; moreover, there is evidence that the DEJ thickness is higher in African Americans than in Caucasians [39].

With intrinsic ageing, a more compact pattern of the fibrous dermal component of PD could be quantified and correlated with decrease in the voids or areas between the fibers of PD on HD-OCT. These areas correspond most probably to the presence of the ground substance consisting in particular of hyaluronic acid and chondroitin sulphate. The IAR loss of the oligosaccharide fraction impacts on the capacity of the PD to retain bound water [32]. On HD-OCT this loss of bound water resulted in higher brightness. The IAR compaction of the dermis is in agreement with other non-invasive technologies such as MPT [23], conventional OCT [33] and HF-US [16-20, 41, 43].

The highest peak after the valley (Fig. 6) corresponds with the junction between $\mathrm{PD}$ and $\mathrm{RD}$ as described for conventional OCT [33]. Moreover, the depth of visibility of fibers in reticular dermis increased dramatically in the OA group. This could be explained by fibre rearrangements and alterations such and glycation of collagen fibers [32, 35].

This pilot study has some limitations: (1) only IAR changes in skin morphology have been studied, with no comparison with sun-exposed areas; (2) only women were assessed; (3) individuals with significant systemic comorbidities were excluded and last but not least (4) no histological validation of IAR qualitative skin changes has been performed.

In conclusion, HD-OCT permits to assess qualitatively and quantitatively in vivo and real time three-dimensional IAR morphological skin changes in high resolution from the skin surface to the superficial reticular dermis. This could offer a new possibility to test the efficacy of different cosmetic products. Moreover, HD-OCT assessment of these changes could provide interesting additional information regarding the biological age of the subject as defined by the Framingham CVD risk score [12]. Furthermore, skin wrinkling at the upper inner arm has been linked to health status [48] and elastin morphology in the PD has been linked to cardiovascular diseases risk [37]. These represent interesting topics for future research.

\section{Conflict of interest None.}

Open Access This article is distributed under the terms of the Creative Commons Attribution 4.0 International License (http://creativecommons.org/licenses/by/4.0/), which permits unrestricted use, distribution, and reproduction in any medium, provided you give appropriate credit to the original author(s) and the source, provide a link to the Creative Commons license, and indicate if changes were made.

\section{References}

1. Baillie L, Askew D, Douglas N, Soyer HP (2011) Strategies for assessing the degree of photodamage to skin: a systematic review of the literature. Br J Dermatol 165:735-742

2. Bernstein EF, Chen YQ, Kopp JB et al (1996) Long-term sun exposure alters the collagen at the PD. Comparison of sun-protected and photoaged skin by nothern analysis, immunohistochemical staining and confocal laser scanning microscopy. J Am Acad Dermatol 34:209-218

3. Bonté F, Noblesse E, Juan M, Verbavatz JM, Dumas M (2009) A study of the importance of aquaporins for human skin. Chin $\mathrm{J}$ Dermatol 42:327-329

4. Boone M, Jemec GB, Del Marmol V (2012) High-definition optical coherence tomography enables visualization of individual cells in healthy skin: comparison to reflectance confocal microscopy. Exp Dermatol 21:740-744

5. Boone M, Norrenberg S, Jemec GB, Del Marmol V (2013) Imaging actinic keratosis by high-definition optical coherence tomography. Histomorphologic correlation: a pilot study. Exp Dermatol 22:93-97

6. Boone M, Norrenberg S, Jemec GB, Del Marmol V (2012) Imaging of basal cell carcinoma by high-definition optical coherence tomography. Histomorphologic correlation: a pilot study. Br J Dermatol 167:856-864

7. Boone M, Norrenberg S, Jemec GB, Del Marmol V (2013) Highdefinition optical coherence tomography: adapted algorithmic method for pattern analysis of inflammatory skin diseases: a pilot study. Arch Derm Res. 305:283-297

8. Boone MA, Jemec GB, Del Marmol V.(2014) Differentiating allergic and irritant contact dermatitis by high-definition optical coherence tomography: a pilot study. Arch Dermatol Res. PubMed PMID: 25186162 (Epub ahead of print)

9. Boone M, Draye JP, Verween G, Pirnay JP, Verbeken G, De Vos D, Rose T, Jennes S, Jemec GB, Del Marmol V (2014) Real-time three-dimensional imaging of epidermal splitting and removal by high-definition optical coherence tomography. Exp Dermatol 23(10):725-730

10. Callaghan TM, Wilhelm KP (2008) A review of ageing and an examination of clinical methods in the assessment of ageing skin. Part 2: clinical perspectives and clinical methods in the evaluation of ageing skin. Int J Cosmet Sci 30:323-332 
11. Conti A, Schiavi ME, Seidenari S (1995) Capacitance, transepidermal water loss and causal level of sebum in healthy subjects in relation to site, sex and age. Int J Cosmetic Sci 17:77-85

12. D'Agostino RB Sr, Vasan RS, Pencina MJ, Wolf PA, Cobain M, Massaro JM, Kannel WB (2008) General cardiovascular risk profile for use in primary care: the Framingham Heart Study. Circulation 117:743-753

13. Gambichler T, Huyn J, Tomi NS, Moussa G, Moll C, Sommer A et al (2006) A comparative pilot study on ultraviolet-induced skin changes assessed by noninvasive imaging techniques in vivo. Photochem Photobiol 82:1103-1107

14. Gambichler T, Matip R, Moussa G, Altmeyer P, Hoffmann K (2006) In vivo data of epidermal thickness evaluated by optical coherence tomography: effects of age, gender, skin type and anatomic site. J Dermatol Sci 44:145-152

15. Gambichler T, Valavanis K, Plura I, Georgas D, Kampilafkos P, Stücker M (2014) In vivo determination of epidermal thickness using high-definition optical coherence tomography. Br J Dermatol 170:737-739

16. Gniadecka M (2001) Effects of ageing on dermal echogenicity. Skin Res Technol 7:204-207

17. Gniadecka M, Serup J, Sondergaard J (1994) Age-related diurnal changes of dermal oedema: evaluation by high-frequency ultrasound. Br J Dermatol 131:849-855

18. Gniadecka M, Gniadecki R, Serup J, Sondergaard J (1994) Ultrasound structure and digital image analysis of the subepidermal low echogenic band in aged human skin: diurnal changes and interindividual variability. J Invest Dermatol 102:362-365

19. Gniadecka M, Jemec GBE (1998) Quantitative evaluation of chronological ageing and photoageing in vivo: studies on skin echogenicity and thickness. Br J Dermatol 139(5):815-821

20. Guittet C, Ossant F, Remenieras JP, Pourcelot L, Berson M (1999) High-frequency estimation of the ultrasonic attenuation coefficient slope obtained in human skin: simulation and in vivo results. Ultrasound Med Biol 25:421-429

21. Kaatz M, Sturm A, Elsner P, Konig K, Buckle R, Koehler MJ (2010) Depth-resolved measurements of the dermal matrix composition by multiphoton laser tomography. Skin Res Technol 16:131-136

22. Kelly RI, Pearse R, Bull RH, Leveque JL, de Rigal J, Mortimer PS (1995) The effects of aging on the cutaneous microvasculature. J Am Acad Dermatol 33:749-756

23. Koehler MJ, König K, Elsner P, Bückle R, Kaatz M (2006) In vivo assessment of human skin aging by multiphoton laser scanning tomography. Opt Lett 31:2879-2891

24. Koehler MJ, Speicher M, Lange-Asschenfeldt S, Stockfleth E, Metz S, Elsner P, Kaatz M, König K (2011) Clinical application of multiphoton tomography in combination with confocal laser scanning microscopy for in vivo evaluation of skin diseases. Exp Dermatol 20:589-594

25. Korde VR, Bonnema GT, Xu W, Krishnamurthy C, RangerMoore J, Saboda K et al (2007) Using optical coherence tomography to evaluate skin sun damage and precancer. Lasers Surg Med 39:687-695

26. Lavker RM, Peishu Z, Gang D (1986) Morphology of aged skin. Dermatol Clin 4:379-389

27. Le Varlet B, Chaudagne C, Saunois A, Barré P, Sauvage C, Berthouloux B, Meybeck A, Dumas A, Bonté F (1998) Agerelated functional and structural changes in human dermo-epidermal junction components. J Invest Dermatol Symp Proc. 3:172-179

28. Li L, Mac-Mary S, Sainthillier JM, Nouveau S, de Lacharriere O, Humbert P (2006) Age-related changes of the cutaneous microcirculation in vivo. Gerontology 52:142-153

29. Li L, Mac-Mary S, Marsaut D, Sainthillier JM, Nouveau S, Gharbi T, de Lacharriere O, Humbert P (2006) Age-related changes in skin topography and microcirculation. Arch Dermatol Res 297:412-416

30. Longo C, Casari A, Beretti F, Cesinaro AM, Pellacani G (2013) Skin ageing: in vivo microscopic assessment of epidermal and dermal changes by means of confocal microscopy. J Am Acad Dermatol 68:e73-e82

31. Mogensen M, Thrane L, Joergensen TM, Andersen PE, Jemec GBE (2009) Optical coherence tomography for imaging of skin and skin diseases. Semin Cutan Med Surg 28:196-202

32. Naylor EC, Watson REB, Sherratt MJ (2011) Molecular aspects of skin ageing. Maturitas 69:249-256

33. Neerken S, Lucassen GW, Bisschop MA, Lenderink E, Nuijs TA (2004) Characterization of age-related effects in human skin: a comparative study that applies confocal laser scanning microscopy and optical coherence tomography. J Biomed Opt 9:274-281

34. Neill US (2012) Skin care in the ageing females: myths and truths. J Clin Invest 222:473-477

35. Pageon H, Zucchi H, Rousset F, Monnier VM, Asselineau D (2014) Skin aging by glycation: lessons from the reconstructed skin model. Clin Chem Lab Med 52:169-174

36. Pauwels M, Rogiers V (2010) Human health safety evaluation of cosmetics in the EU: a legally imposed challenge to science. Toxicol Appl Pharmacol 243:260-274

37. Purba MB, Kouris-Blazos A, Wattanapenpaiboon N, Lukito W, Rothenberg E, Steen B, Wahlqvist ML (2001) Can skin wrinkling in a site that has received limited skin exposure be used as a marker of health status and biological age? Age Ageing 30:227-234

38. Puschmann S, Rahn CD, Wenck H, Gallinat S, Fischer F (2012) Approach to quantify human dermal skin aging using multiphoton laser scanning microscopy. J Biomed Opt 17(3):036005

39. Querleux B, Baldeweck T, Diridollou S, de Rigal J, Huguet E, Leroy F, Halloway Barbosa V (2009) Skin from various ethnic origins and ageing: an in vivo cross-sectional multimodality imaging study. Skin Res Technol 15:306-313

40. Raphael AP, Kelf TA, Wurm EMT, Zvyagin AV, Soyer HP, Prow TW (2013) Computational characterization of reflectance confocal microscopy features reveals potential for automated photoageing assessment. Exp Dermatol 22:458-463

41. Sandby-Moller J, Wulf HC (2004) Ultrasonographic subepidermal low-echogenic band, dependence of age and body site. Skin Res Technol 10:57-63

42. Sauermann K, Clemann S, Jaspers S, Gambichler T, Altmeyer P, Hoffmann K, Ennen J (2002) Age related changes of human skin investigated with histometric measurements by confocal laser scanning microscopy in vivo. Skin Res Technol 8:52-56

43. Seidenari S, Pagnoni A, Di Nardo A, Giannetti A (1994) Echographic evaluation with image analysis of normal skin: variations according to age and sex. Skin Pharmacol 7:201-209

44. Serup J (2001) Efficacy testing of cosmetic products. Skin Res Technol 7:141-151

45. Sougrat R, Morand M, Gondran C, Barré P, Gobin R, Bonté F et al (2002) Functional expression of AQP-3 in human skin epidermis and reconstructed epidermis. J Invest Dermatol 118:678-685

46. Vierkötter A, Ranft U, Krämer U, Sugiri D, Reimann V, Krutmann J (2009) The SCINEXA: a novel validated score to simultaneously assess and differentiate between intrinsic and extrinsic skin ageing. J Dermatol Sci 53:207-211

47. Vybohova D, Mellova Y, Adamicova K, Adamkov M, Heskova G (2012) Qualitative changes of the capillary bed in aging human skin. Histol Histopathol 27:961-967

48. Waaijer MEC, Gunn DA, Catt SD, van Ginkel M, de Craen AJM, Hudson NM, van Heemst D, Slagboom PE, Westendorp RGJ, Maier AB (2012) Morphometric skin characteristics dependent 
on chronological and biological age: the Leiden Longevity Study. Age (Dordr) 34(6):1543-1552

49. Waller JM, Maibach HI (2005) Age and skin structure and function, a quantitative approach (I): blood flow, $\mathrm{pH}$, thickness and ultrasound echogenicity. Skin Res Technol 11:221-235

50. Watson RE, Griffiths CE, Craven NM, Shuttleworth CA, Kielty CM (1999) Fibrillin-rich microfibrils are reduced in photoaged skin. Distribution at the dermo-epidermal junction. J Invest Dermatol 112:782-787

51. Wurm EMT, Longo C, Curchin C, Soyer HP, Prow TW, Pellacani $G$ (2012) In vivo assessment of chronological ageing and photoageing in forearm skin using reflectance confocal microscopy. Br J Dermatol 167:270-279 